\title{
EVALUATION OF ENERGY OBTAINED FROM SOLAR PANEL LOADED DIRECTLY AND WITH MICROINVERTER
}

\author{
Ilze Pelece, Henriks Putans, Imants Ziemelis, Liene Kancevica, Semjons Ivanovs \\ Latvia University of Life Sciences and Technologies, Latvia \\ ilze.pelece@1lu.lv, henriksooo@inbox.lv, liene.kancevica@1lu.lv, semjons@apollo.lv
}

\begin{abstract}
The article deals with use of solar panels directly for heating of water with active resistance. For achieving the maximum power it is important to use correct value of resistance. At optimal working conditions (most important is high solar irradiance) this value can be obtained from data given by the panel's producers, but for lower solar irradiances the optimal resistance is higher than that. In this article the energy amount obtained from a solar panel loaded with constant resistance (long-term optimal for local conditions) is compared with that obtained from an equal panel using the solar invertor Enphase with MPPM function. The Enphase Microinverter converts the DC output of the PV module into grid-compliant AC power. Manufacturers claim that in addition to performing the DC to AC conversion, it maximizes energy production by using a sophisticated Maximum Power Point Tracking (MPPT) algorithm. This integrated system maximizes the energy harvest, increases the system reliability, and simplifies the design, installation and management. We wanted to check how big the benefit from use of this Microinverter is. The obtained results show that with constant active resistance the harvested energy amount from July till October is approximately $77 \%$ from that registered with the Enphase Microinverter at the same time.
\end{abstract}

Keywords: PV panel, water heating, active load, microinverter.

\section{Introduction}

Solar energy is used not only in southern countries, where solar irradiation is high, but also in northern ones, including Latvia, located at $57^{\circ}$ Northern latitude. In this latitude the height of the sun and therefore also solar irradiance is lower than in southern countries, but in summer days are longer, up to 17 hours. Several authors $[1 ; 2]$ have studied use of photovoltaics in Latvia and stated that this is one of ways to diminish $\mathrm{CO}_{2}$ emissions, but they also found that energy gain from photovoltaic is less than expected [2].

One of most common applications of solar energy is a solar panel or photovoltaic (PV), which converts solar energy into electric one. At most common cases electricity produced by a solar panel is used instead or in grid with traditional electricity, therefore, it must be transformed from direct current (DC) to alternate one (AC). In up-to-date systems this conversion is done by micro inverters, providing also maximal energy harvest using Maximum Power Point Tracking (MPPT) techniques $[3 ; 4]$. But the main disadvantage of micro inverters is their cost. Use of micro inverters increases the cost of the obtained energy more than twice [5].

On the other hand, there are situations, where use of micro inverters is not necessary, because also direct current can be used and it is not important how stable it is. One of such applications is electrical heating of water [6]. In this case, simply constant resistance can be used, but here is a problem: what value of resistance to be used. At optimal working conditions (solar irradiance, ambient temperature etc.) for given solar panel the optimal resistance can be obtained from the technical data provided by the panel's producers. At different circumstances current-voltage characteristic of the panel (Fig. 1.), and therefore also the optimal resistance is different [7].

It is very important in Latvia and other northern countries, where on clear summer midday irradiation at the optimally positioned solar panel can be $1000 \mathrm{~W} \cdot \mathrm{m}^{-2}$ [8], but in spring, autumn and especially winter irradiation is much smaller because of the low height of the sun. Also, in summer solar radiation often is small because of clouds. It can be important also in southern countries, if a stationary positioned solar panel is used - then irradiation in the morning and evening is significantly smaller. Few authors [6;9] found that long-term optimal load is approximately 4to $4.5 \Omega$ for a standard panel. Important question is how advantages of use of microinverters depend on conditions of use of solar panels, especially solar irradiation. Are they greater at high energy conditions or at low, or independent? We did not find an answer to this question in literature, therefore, it is one of the tasks of this article.

In this article the energy harvest from panels used with a micro-inverter and those loaded with constant resistance are compared. 


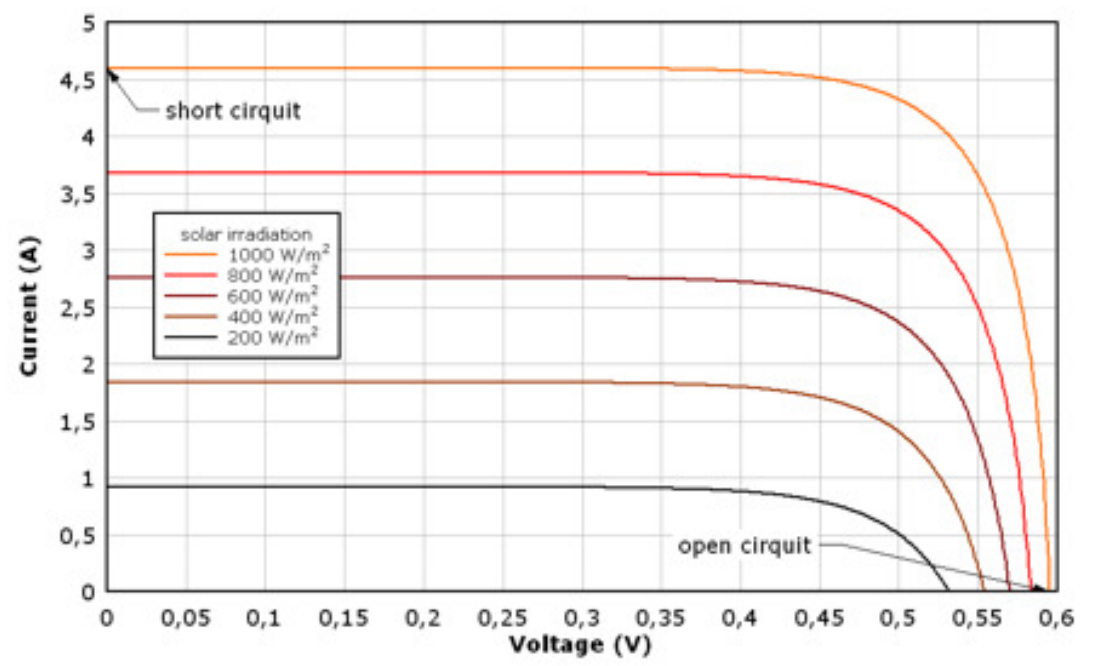

Fig. 1. Current-voltaic characteristics of PV panel [7]

\section{Materials and methods}

Studies are carried out on the roof of the Ulbroka Scientific Centre (56 $\left.56^{\prime} \mathrm{N} 24^{\circ} 17^{\prime} \mathrm{E}\right)$.

Four solar panels Solet 60.6-WF-250 are used in this work. Panels are mounted stationary faced to the south at 40 degrees tilt angle. The technical characteristics of the panels are given in Table 1.

Table 1

Main parameters of solar panel Solet 60.6-WF-250

\begin{tabular}{|l|c|c|}
\hline \multicolumn{1}{|c|}{ Parameter } & Designation & Value \\
\hline Maximal power & $P_{\max }$ & $255 \mathrm{~W}$ \\
\hline Voltage at maximum power point & $V_{\operatorname{mpp}}$ & $30.9 \mathrm{~V}$ \\
\hline Open voltage & $V_{o c}$ & $38.4 \mathrm{~V}$ \\
\hline Current at maximum power point & $I_{m p p}$ & $8.06 \mathrm{~A}$ \\
\hline Short circuit current & $I_{s c}$ & $8.6 \mathrm{~A}$ \\
\hline Thermal coefficient of power & $\% / \mathrm{K}$ & $(-0.47)$ \\
\hline Size & $\mathrm{mm}$ & $1640 \times 992 \times 45$ \\
\hline Mass & $\mathrm{kg}$ & 22 \\
\hline Energy conversion ratio & $\%$ eff & 15 \\
\hline
\end{tabular}

The panels are shown in Fig. 2.

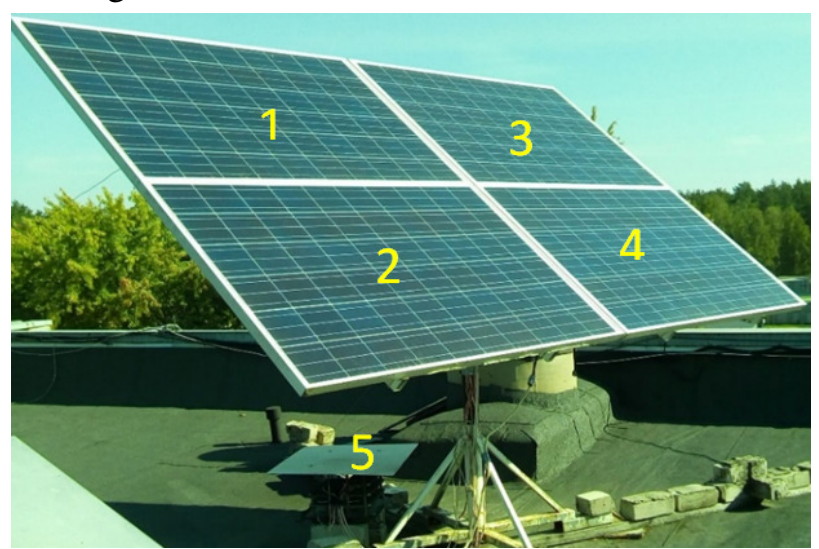

Fig. 2. Solar panels: 1 - loaded with $4.5 \Omega$ resistance; 2 - loaded with $6.5 \Omega$ resistance;

3, 4 - connected to the grid through the micro inverter Envoy; 5 - resistance magazine

Four solar panels are used. Two of them are loaded with constant resistance, one with $4.5 \Omega$ and the other with $6.5 \Omega$. The other two panels are connected to the electricity grid through the micro invertor Envoy. The energy output from all panels has been registered. 
Measurements were carried out from 20 July till 31 October 2019. After every 6 min using a data logger HOBO voltage at constant load resistances was measured. The circuit diagram of these measurements is given in Fig. 3.

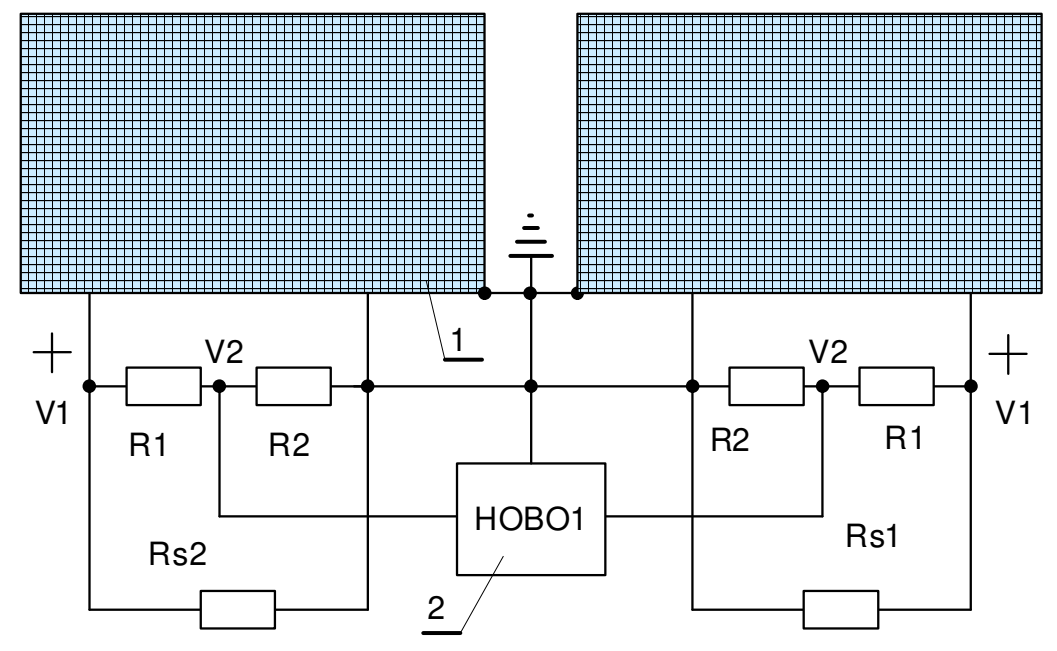

Fig. 3. Circuit diagram for measuring voltage on load resistances: 1 - solar panel; 2 - data logger HOBO

Then the power of the panel is calculated as

$$
P_{i}=\frac{\left(U_{H i} / k\right)^{2}}{R_{S i}},
$$

where $P_{i}$ - power, W;

$U_{H i}-$ voltage measured with the HOBO logger, V;

$k$ - voltage divider partition coefficient;

$R_{S i}$ load resistance, $\Omega$.

Daily energy sum then can be obtained as

$$
Q=\frac{\Sigma P_{i}}{N},
$$

where $Q$-energy, produced in the day, Wh;

$P_{i}-$ power, calculated from (1), W;

$N$ - number of measurements in one hour.

Other two panels are identical to the first ones, but they are connected to the electricity grid with the Enphase Microinverter System. This system consists of the Enphase Microinverter (we used Enphase M215 microinverters), Enphase Envoy Communications Gateway and Enphase Enlighten web-based monitoring and analysis software.

The Enphase Microinverter converts the DC output of the PV module into grid-compliant AC power. In addition to performing the DC to AC conversion, it maximizes the energy production by using a sophisticatedMaximum Power Point Tracking (MPPT) algorithm. The circuit diagram for these two panels is given in Fig. 4.

Daily energy sums were obtained from the Enphase Enlighten analysis software.

\section{Results and discussion}

As with the Envoy the energy produced by two panels is measured, it is compared to the energy produced from two panels. The daily energy sums obtained from the solar panels loaded with constant resistance are very similar to each other (Fig. 5), but the panel loaded with $4.5 \Omega$ gives little bit more energy at more sunny days than that with $6.5 \Omega$ and vice versa at low radiance circumstances. 


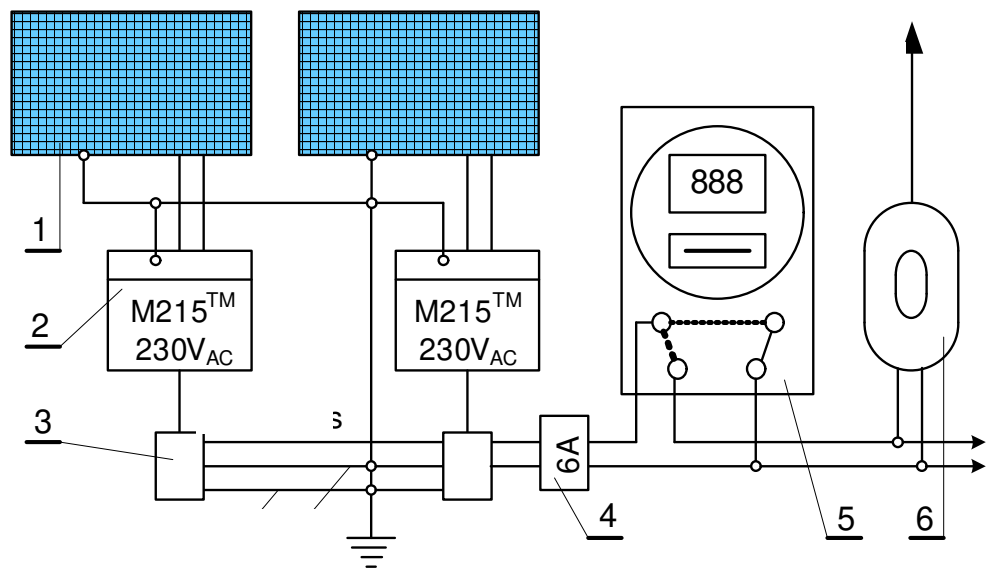

Fig. 4. Circuit diagram for measuring with Enphase System: 1 - solar panels; 2 - microinverters; 3 - current dividers; 4 - automatic switch; 5 -electromechanical energy meter; 6 - enphase Envoy rooter
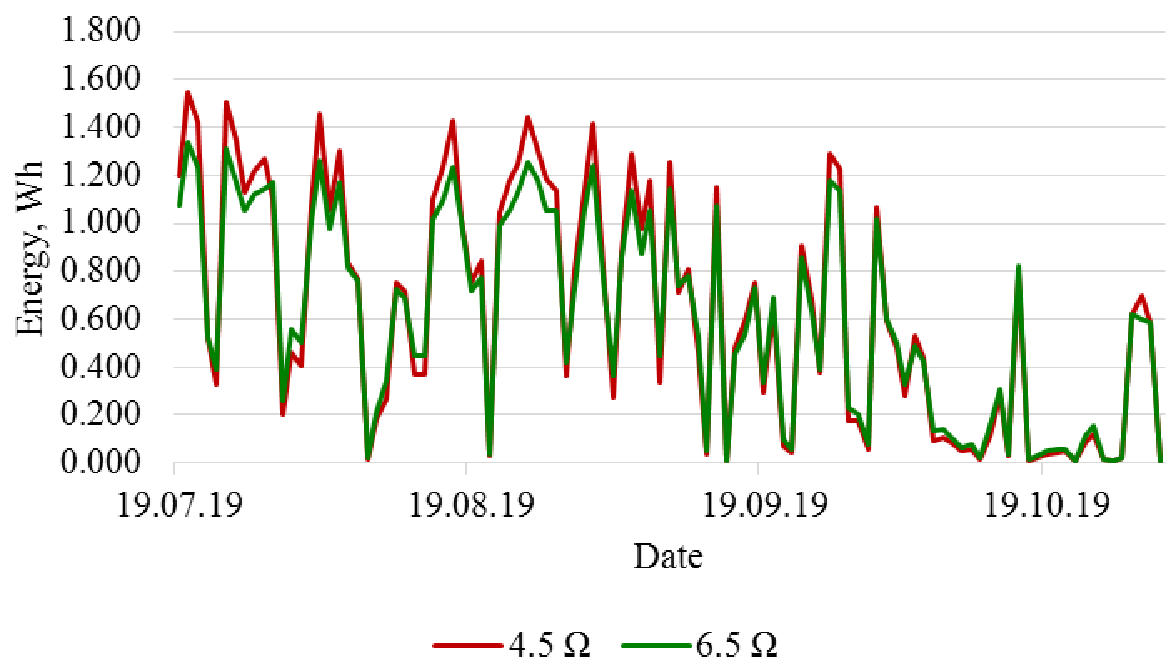

Fig. 5. Daily energy sums obtained from with constant resistance loaded solar panels

Therefore, the energy registered with the Envoy is compared to double energy produced by the panel loaded with $4.5 \Omega$ resistance and with the sum of with $4.5 \Omega$ and with $6.5 \Omega$ loaded panels (Fig. 6).

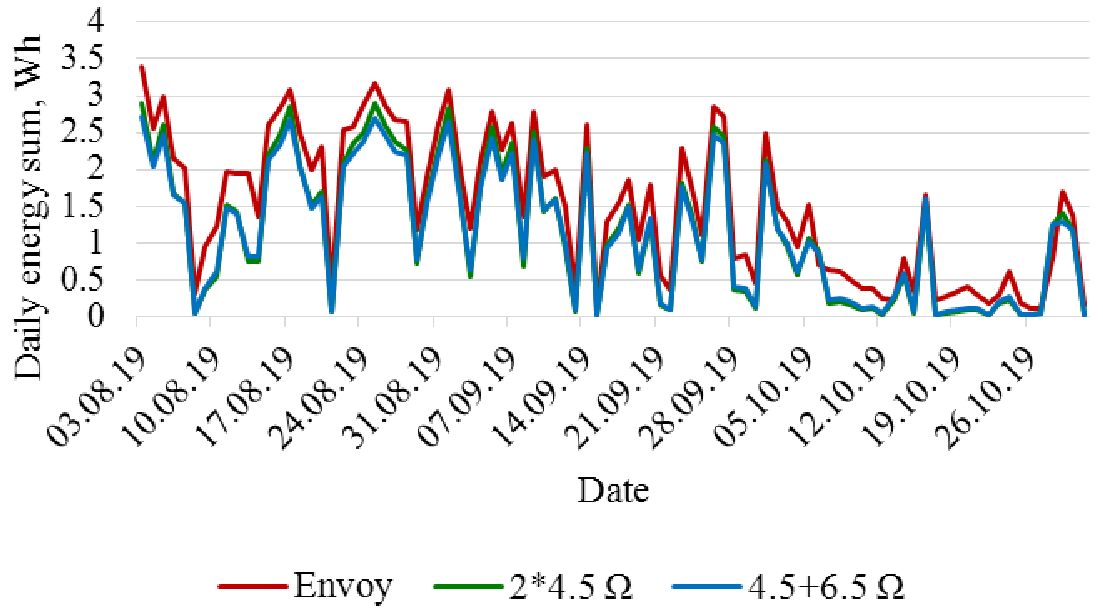

Fig. 6. Daily energy sums obtained from solar panels 
It can be seen from the graph that the Envoy collected slightly more energy both at high and low irradiance conditions.

Another way how to compare solar panels working at equal conditions is to plot daily energy sums obtained by one of them via sums obtained from the other, then the trend line of the graph allows to compare them. Fig. 7 shows the graph, where on $\mathrm{x}$ axis are the daily energy sums registered with the Envoy, but on y axis are the daily energy sums obtained from with constant resistance loaded solar panels: green dots and line from two panels loaded with $4.5 \Omega$ resistance, brown dots and line from one panel loaded with $4.5 \Omega$ resistance and the other one with $6.5 \Omega$ resistance.

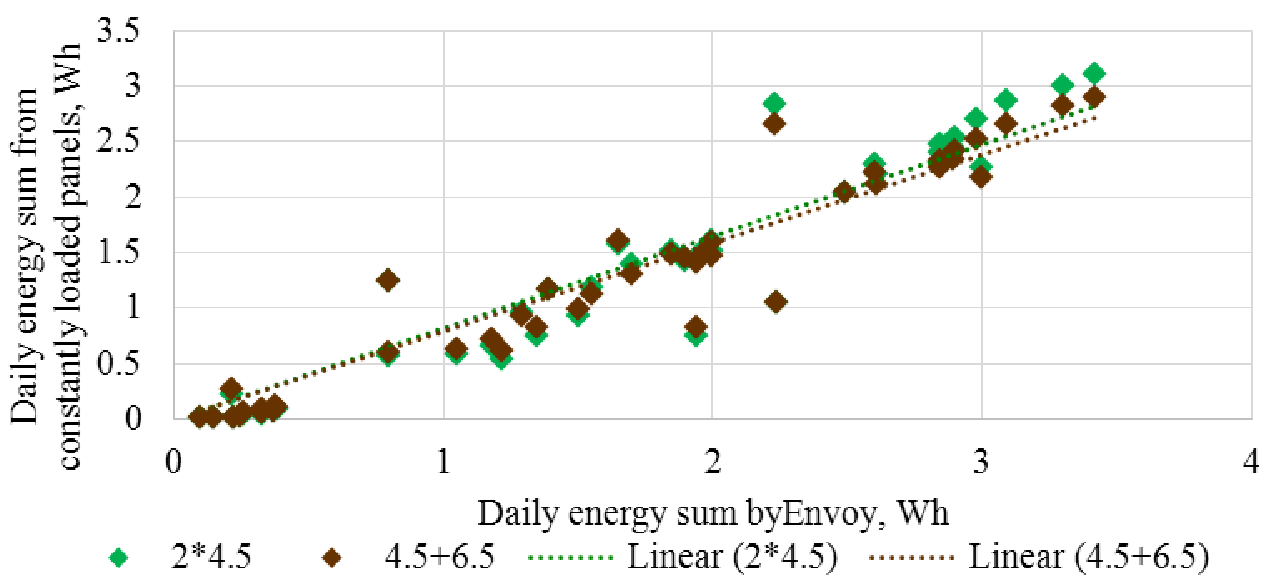

Fig. 7. Daily energy sums obtained from constantly loaded solar panels via sums registered by Envoy

Then trendline equation for $2 \cdot 4.5 \Omega$ resistance is $E_{c}=0.8244 \cdot E_{E}$ with the determination factor $R^{2}=0.90$, and for one panel with $4.5 \Omega$ load and the other with $6.5 \Omega$ load it is $E_{c}=0.79 \cdot E_{E}$ with $R^{2}=0.91$, where $E_{c}$ is the daily energy sum obtained from a constantly loaded solar panel and $E_{E}$ is the daily energy sum registered by Envoy.

Similar results can be obtained, if the energy sums obtained in all 105 day period are analysed. These sums are shown in Table 2. The energy sums from one panel loaded with $4.5 \Omega$ or $6.5 \Omega$ load are not comparable with the sum registered by the Envoy, because the Envoy registers energy produced by two panels.

Two panels loaded with $4.5 \Omega$ resistance give $133.54 \mathrm{Wh}$ in all period together, what is $79 \%$ from 169.52 Wh registered by the Envoy. One panel loaded with $4.5 \Omega$ resistance and one with $6.5 \Omega$ resistance give $130.56 \mathrm{Wh}$ what is $77 \%$ from energy registered by the Envoy.

The difference of the results obtained from the graph (Fig. 7) can be explained with higher impact of days with high energy amount on the whole sum.

\section{Amount of energy obtained in all 105 day period}

Table 2

\begin{tabular}{|c|c|c|}
\hline Energy & Wh & \% \\
\hline Envoy & 169.52 & 100 \\
\hline $4.5 \Omega$ & 66.77 & 78.8 \\
\hline $6.5 \Omega$ & 63.79 & 77.0 \\
\hline$(2 * 4.5) \Omega$ & 133.54 & 79 \\
\hline$(4.5+6.5) \Omega$ & 130.56 & 77 \\
\hline
\end{tabular}

Although panels with the Enphase Microinverter System (EMS) produce more energy than constantly loaded panels both at high energy and low energy conditions, the ratio between the daily energy sums depends on the sum. Fig. 8 shows dependence of the ratio between the daily energy sums obtained from the panel loaded with constant $4.5 \Omega$ resistance to that from the panel with the Enphase Microinverter System on the daily amount of energy obtained with EMS. 


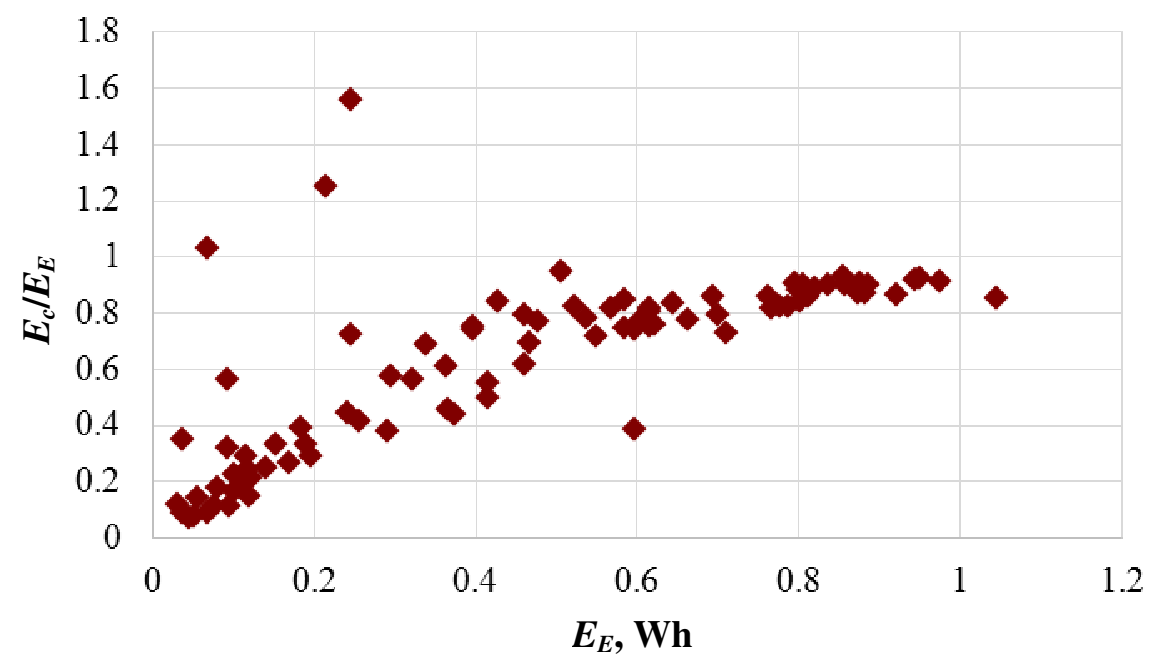

Fig. 8. Dependence of the ratio of energy from the panel loaded with constant $4.5 \Omega$ resistance to that with microinverteron energy obtained with the microinverter

It can be seen from the graph that the ratio is smaller, if the daily amount of energy is small and grows rather rapidly with the energy sum, but if the daily energy sum is high, the ratio is almost constant. It means that advantages of use of the microinverter are greater at high energy conditions.

\section{Conclusions}

1. Similar solar panels used with the Enphase Microinverter System produce more energy than loaded with constant resistance, both at high and low energy conditions.

2. Advantages of the Enphase Microinverter System are greater at conditions of high energy gain.

3. The panels loaded with constant $4.5 \Omega$ resistance, what is optimal for given conditions, produced $79 \%$ of energy amount produced by the panels with the Enphase Microinverter System.

\section{References}

[1] Njakou Djomo S., Blumberga D. Electricity from the Sun: is it attractive for Latvia? Life-cycle assessment of photovoltaic systems. Latvian Journal of Physics and Technical Sciences; ISSN 0868-8257; Vol. 2005, issue 4, pp. 3-12.

[2] Lauka D., Pakere I., Blumberga D. First solar power plant in Latvia. Analysis of operational data. Energy Procedia 147 (2018), pp. 162-165.

[3] Hong Y.Y., Buay P.M.P. Robust design of type-2 fuzzy logic-based maximum power point tracking for photovoltaics. Sustainable Energy Technologies and Assessments, vol. 38 (2020) 100669.

[4] Emmanuel M., Rayudu R., Welch I. Modelling impacts of utility-scale photovoltaic systems variability using the wavelet variability model for smart grid operations. Sustainable Energy Technologies and Assessments, Volume 31, February 2019, pp. 292-305.

[5] 2018 Solar Panels Cost Per Watt Guide. [online] [13.02.2018]. Available at: https://powerscout.com/site/2018-solar-panel-cost-per-watt

[6] Pelece I., Ziemelis I., Putans H., Snegovs A. Improvement of efficiency of PV panels for water heating by changing heater resistance. 18th International scientific conference "Engineering for Rural Development": proceedings, Jelgava, Latvia, May 22-24, 2019 Latvia University of Life Sciences and Technologies. Faculty of Engineering. - Jelgava, 2019, Vol. 18, pp. 1430.-1434.

[7] Solar cells. [online] [13.02.2018]. Available at: http://www.pvresources.com/en/solarcells/solarcells.php

[8] State limited Liability Company "Latvian Environment, Geology and Meteorology Centre" [online] [13.02.2018]. Available at: https://www.meteo.lv/en/

[9] Salilih E.M., Birhane Y.T. Modeling and Analysis of Photo-Voltaic Solar Panel under Constant Electric Load. Hindawi Journal of Renewable Energy Volume 2019, Article ID 9639480, 10 pages. 